\title{
Intraoperative Complications during Sinus Floor Elevation Using Two Different Ultrasonic Approaches: A Two-Center, Randomized, Controlled Clinical Trial
}

\author{
Claudio Stacchi, DDS, MSc; ${ }^{\star}$ Tomaso Vercellotti, MD, DDS; ${ }^{\dagger}$ Annamaria Toschetti, DDS; $;$ \\ Stefano Speroni, DDS, PhD, MSc; ${ }^{\lessgtr}$ Stefano Salgarello, MD, DDS, MSc; ${ }^{\Im}$ Roberto Di Lenarda, DDS, MSc**
}

\begin{abstract}
Purpose: The aim of this study was to assess the prevalence of intraoperative complications during maxillary sinus elevation with lateral approach using a piezoelectric device with two different surgical techniques.

Materials and Methods: Antrostomies were randomly performed by outlining a window (group A, 36 patients) or by eroding the cortical wall with a grinding insert until the membrane was visible under a thin layer of bone, before outlining the window (group B, 36 patients). Occurrence of membrane perforation, laceration of vascular branches, and surgical time was recorded.

Results: Seventy-two patients underwent sinus floor elevation: four perforations (11.1\%) were observed in group A (two occurred during elevation with hand instruments) and zero perforations in group B $(p<.05)$. No evidence of vascular lacerations was registered in both groups. A clinically insignificant but statistically shorter surgical time was recorded in group A (9.2 \pm 3.7 minutes) than in group B $(13.3 \pm 2.4$ minutes; $p<.05)$.

Conclusions: Within the limits of the present study, it may be concluded that ultrasonic erosion of the lateral wall of the sinus is a more predictable technique than piezoelectric outlining of a bone window in preventing from accidental perforations of Schneiderian membrane during sinus augmentation procedures.
\end{abstract}

KEY WORDS: lateral antrostomy, membrane perforation, piezosurgery, randomized clinical trial

\section{INTRODUCTION}

Tooth loss results physiologically in a significant remodeling of the alveolar ridge. Bone resorption process

\footnotetext{
${ }^{*}$ Contract professor, Department of Medical, Surgical and Health Sciences, University of Trieste, Trieste, Italy; ${ }^{\dagger}$ honorary professor, Eastman Dental Institute, London, UK; ${ }^{*}$ lecturer, Department of Medical, Surgical and Health Sciences, University of Trieste, Trieste, Italy; ${ }^{\S}$ contract professor, Department of Surgical, Reconstructive and Diagnostic Sciences, University of Milano, Milano, Italy; 'associate professor, Department of Surgical, Medical, Radiological Sciences and Public Health, University of Brescia, Brescia, Italy; ${ }^{*}$ full professor, Department of Medical, Surgical and Health Sciences, University of Trieste, Trieste, Italy
}

Reprint requests: Dr. Claudio Stacchi, DDS, MSc, Department of Odontology and Stomatology - University of Trieste, Piazza Ospitale, 1-34125 Trieste, Italy; e-mail: claudio@stacchi.it

(c) 2013 Wiley Periodicals, Inc.

DOI 10.1111/cid.12136 begins immediately after extraction and, within 2 years, leads to an average 40 to $60 \%$ reduction in horizontal and vertical dimensions of the alveolar ridge. ${ }^{1-3}$

In the posterior upper jaw, postextractive bone remodeling is associated with a progressive sinus pneumatization, often resulting in the impossibility to place implants in these sites. ${ }^{4,5}$

Sinus floor elevation is a currently well-accepted procedure to treat bone atrophy in posterior maxilla; it was orally introduced by Tatum at Alabama Implant Congress in $1976^{6}$ and first published by Boyne and James (1980).?

The traditional technique consists in a modified Caldwell-Luc approach, where access to maxillary sinus is obtained by drilling a bone window in lateral sinus wall; then, Schneiderian membrane is carefully detached and elevated from sinus floor in order to insert grafting 
materials, including autogenous bone, allografts, xenografts, or alloplasts. Implants can be inserted simultaneously, or in a second stage if residual bone is not sufficient to obtain an adequate primary stability; their long-term clinical outcomes have been demonstrated to be highly predictable. ${ }^{8}$

Nevertheless, sinus augmentation with lateral approach presents several possible intraoperative complications: fractures of residual alveolar ridge, damage to adjacent teeth, and hemorrhagic problems $s^{9,10}$ as anastomosis between posterior superior alveolar artery and infraorbital artery is always present in the lateral sinus wall area. ${ }^{11}$ Damage to these arteries may occur during antrostomy, causing profuse bleeding and difficulties in completing surgical procedure. $^{9,10}$

However, the most frequent intraoperative complication is Schneiderian membrane perforation; its prevalence, with rotary instrumentation, has been reported to vary from $5^{12}$ to $56 \% .^{13}$

Torella and colleagues ${ }^{14}$ proposed the use of a standard ultrasonic scaler in performing antrostomy in order to reduce risks of membrane perforation and vessels damage. However, cutting efficiency of standard ultrasonic instruments is not sufficient to perform osteotomies in thick bone exposing tissues, at the same time, to serious risks of overheating.

In 2001, Vercellotti and colleagues ${ }^{15}$ introduced the piezoelectric bony window osteotomy and sinus membrane elevation using an ultrasonic device specially designed for osseous surgery. Piezoelectric surgery units use low-frequency ultrasonic vibrations that scatter upon contact with soft tissue and, thus, reduce the risk of sinus membrane perforation. In the last decade, several studies were performed on sinus elevation with ultrasonic techniques, reporting a perforation rate ranging from $4{ }^{16}$ to $31 \% .{ }^{17}$ Two main surgical approaches in performing piezoelectric antrostomy have been described in literature: an outlining of the bony window on the lateral wall of the sinus ${ }^{15}$ or an erosion of the cortical plate until the dark color of the sinus cavity appears under a thin layer of bone, before outlining the window. $^{18,19}$

The aim of this study is to assess the prevalence of intraoperative complications during maxillary sinus floor elevation with ultrasonic lateral approach using a piezoelectric device with the above-mentioned surgical techniques.

\section{MATERIALS AND METHODS}

\section{Study Population}

This randomized controlled trial (RCT) included 72 adult patients with a severe maxillary atrophy (crestal height $<5 \mathrm{~mm}$ - class V-VI of Cawood and Howell classification ${ }^{20}$ ) and needing sinus floor elevation to allow for a fixed rehabilitation with osseointegrated implants. Patients were consecutively recruited and treated at one university center and one private dental office from 2008 to 2012. At each center, there was a local independent assessor who recorded all outcome measures. All the clinical procedures were performed in full accordance with the Declaration of Helsinki (2008) and the Good Clinical Practice Guidelines. Each patient received thorough explanations on the protocol and provided a written informed consent before participation.

General exclusion criteria were the following: acute myocardial infarction within the past 6 months, uncontrolled coagulation disorders, uncontrolled metabolic diseases (e.g., diabetes mellitus and bone pathologies), radiotherapy to the head/neck district within the past 24 months, present or past treatment with intravenous bisphosphonates, psychological or psychiatric problems, and alcohol or drug abuse. Local exclusion criteria were presence of uncontrolled or untreated periodontal disease (Full Mouth Plaque Score $<25 \%$ ) and/or presence of active sinusal diseases or disorders (e.g., acute sinusitis, retained root tips, polyps, cysts in the antral cavity).

At the initial visit, all subjects underwent a clinical and occlusal examination, and panoramic radiographs were evaluated. Then, a prosthetic assessment with diagnostic waxing was carried out, and a cone beam computed tomography scan with a template was performed in order to study the programmed implant sites.

A computer-generated table, distributing all the patients into two groups (A and B), was prepared using a balanced, randomly permuted block approach (http:// www.randomization.com).

\section{Treatment}

Surgical procedures were performed by two expert clinical operators with previous experience in sinus floor elevation with ultrasonic techniques. Patients were premedicated with $2 \mathrm{~g}$ of amoxicillin/clavulanate potassium (or clindamycin $600 \mathrm{mg}$ if they are allergic to penicillin) 1 hour prior to the surgery. Under local anesthesia (articaine $\mathrm{HCl} 40 \mathrm{mg} / \mathrm{ml}$ with epinephrine 


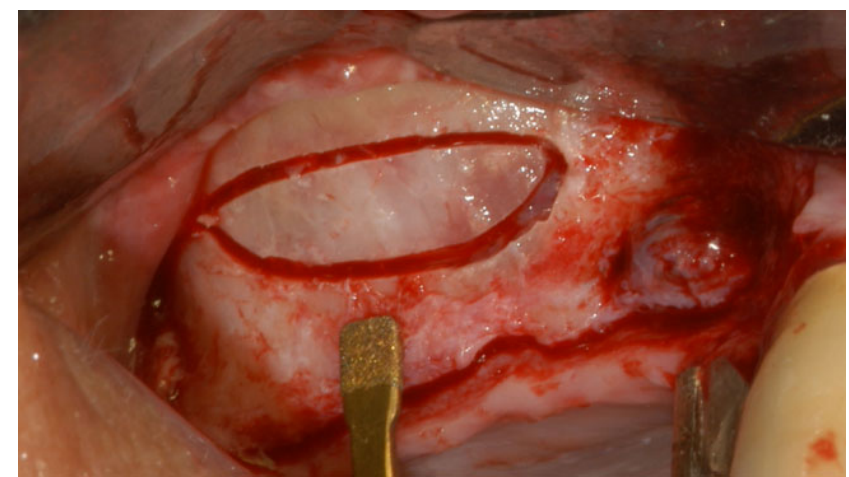

Figure 1 Bone window outlining on the lateral wall of the sinus using an OT1 ultrasonic insert.

1:100,000; Alfacaina, Weimer Pharma, Rastatt, Germany), a full thickness mucoperiostal flap was elevated, and the underlying bone crest was exposed for osteotomy. After flap reflection, the randomization envelope was opened by an independent assessor, and the assigned treatment was revealed to the surgeon. In group $\mathrm{A}$, a window was outlined on the lateral wall of the sinus using an OT1 ultrasonic insert (power setting: Cortical) (Piezosurgery 3, Mectron, Carasco, Italy) (Figure 1). Once the bony window was completely separated from the adjacent bone, an EL1 insert (power setting: Special; Mectron, Carasco, Italy) was used perimetrically to separate the membrane from the bone (Figure 2); its elevation was then completed with hand instruments (Figure 3). In group B, the lateral antrostomy began by eroding the bone with an OP3 insert (power setting: Cortical; Mectron) until the dark color of the sinus cavity appeared under a thin layer of bone (Figures 4 and 5). An OT1 insert was then used to

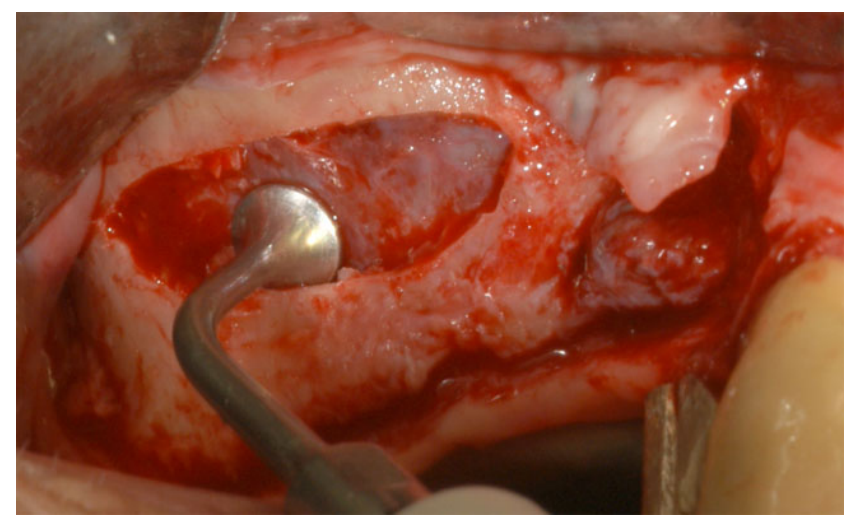

Figure 2 Separation of the membrane from the bone with an EL1 ultrasonic insert.

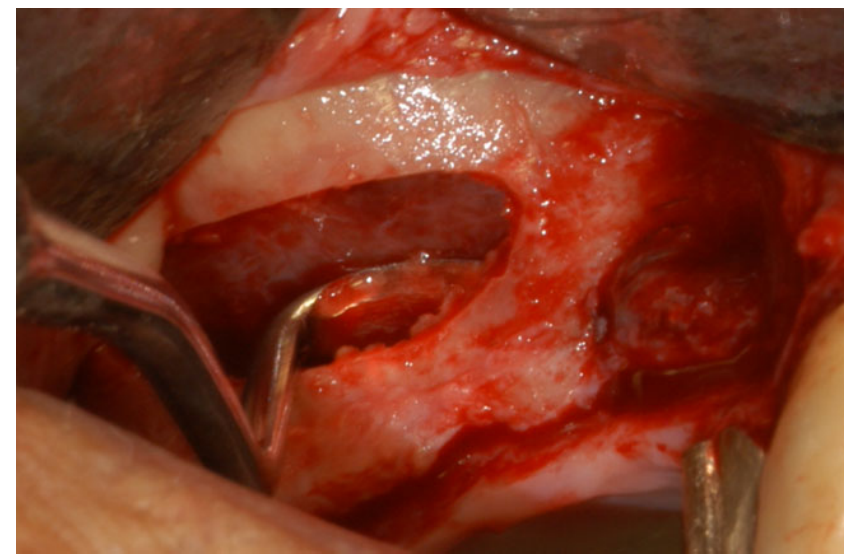

Figure 3 Membrane elevation with hand instruments.

complete the osteotomy (power setting: Cortical), followed by membrane separation and elevation with EL1 and hand instruments as previously described (Figures 6 and 7). The presence of underwood septa and vascular branches was recorded; in this last case, the ultrasonic handpiece was carefully used to isolate them without damages. Sinuses were finally grafted with xenografts or allografts; where a perforation was present, it was covered with a resorbable collagen membrane prior to grafting the sinus. Tears and perforations were determined by direct visualization and the Valsalva maneuver.

As an additional record, surgical time from the beginning of the antrostomy to the moment in which the membrane was completely elevated was registered for both techniques.

The lateral antrostomy was finally covered with a collagen membrane, and the flaps were sutured with a synthetic monofilament.

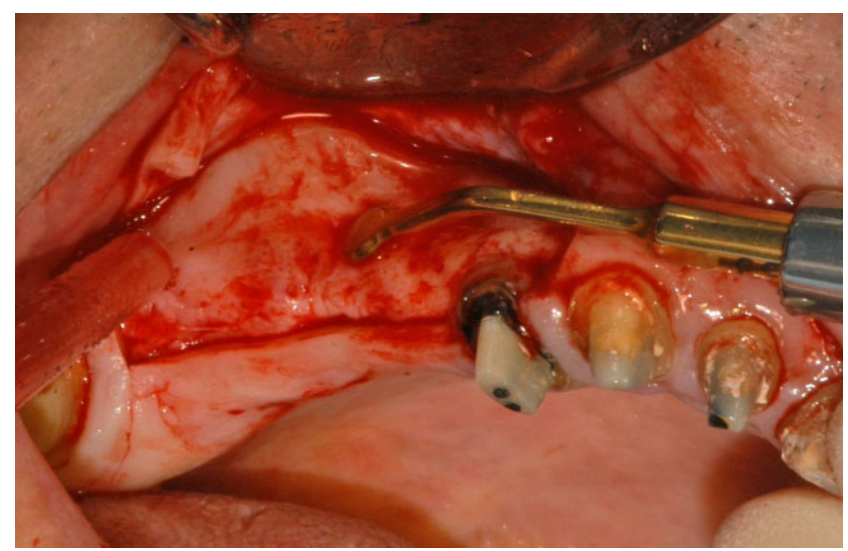

Figure 4 Erosion of the cortical on the lateral wall of the sinus using an OP3 ultrasonic insert. 


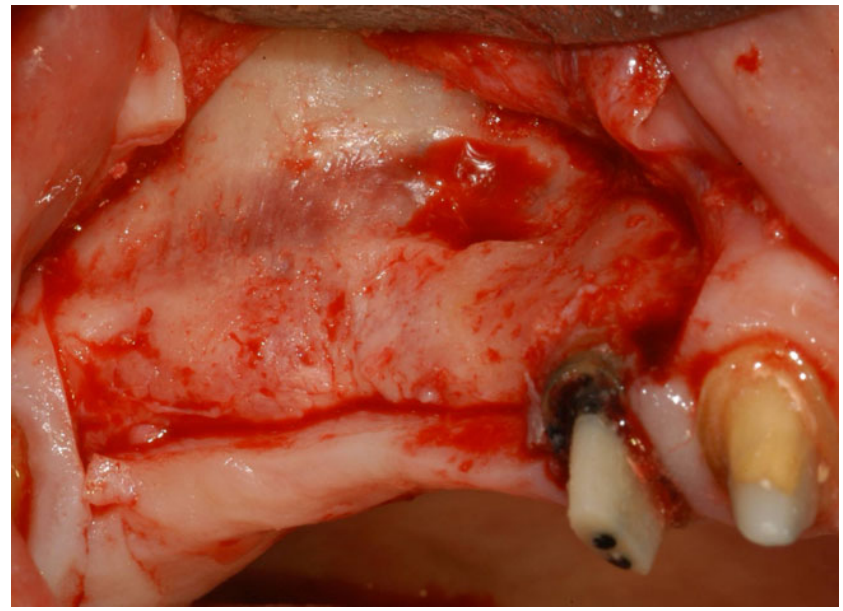

Figure 5 Thickness of the cortical wall has been reduced until the dark color of the sinus cavity appeared under a thin layer of bone.

Patients were prescribed with antibiotics for 1 week (amoxicillin/clavulanate potassium $2 \mathrm{~g}$ per day or clindamycin $600 \mathrm{mg}$ per day if allergic to penicillin), with nonsteroidal anti-inflammatory agents as needed, and with a $0.12 \%$ chlorhexidine mouth rinse three times a day for 2 weeks. All patients were also recommended to sneeze with the mouth open and to avoid nose blowing for 2 weeks to prevent unnecessary pressure on the sinus membrane.

\section{Outcome Measures}

This study tested the null hypothesis that there was no difference in the prevalence of intraoperative complications between the two surgical techniques against the alternative hypothesis of a difference.

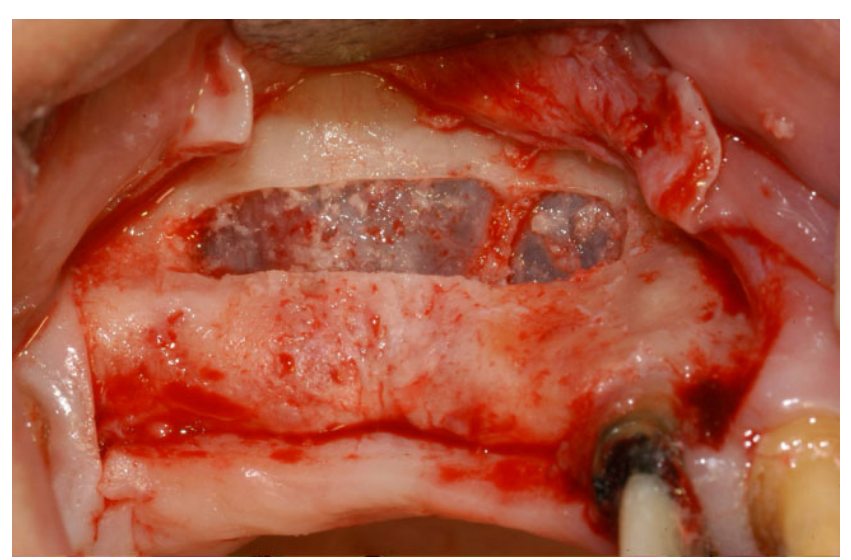

Figure 6 Antrostomy has been completed using an OT1 ultrasonic insert (the presence of an Underwood septum is evident).

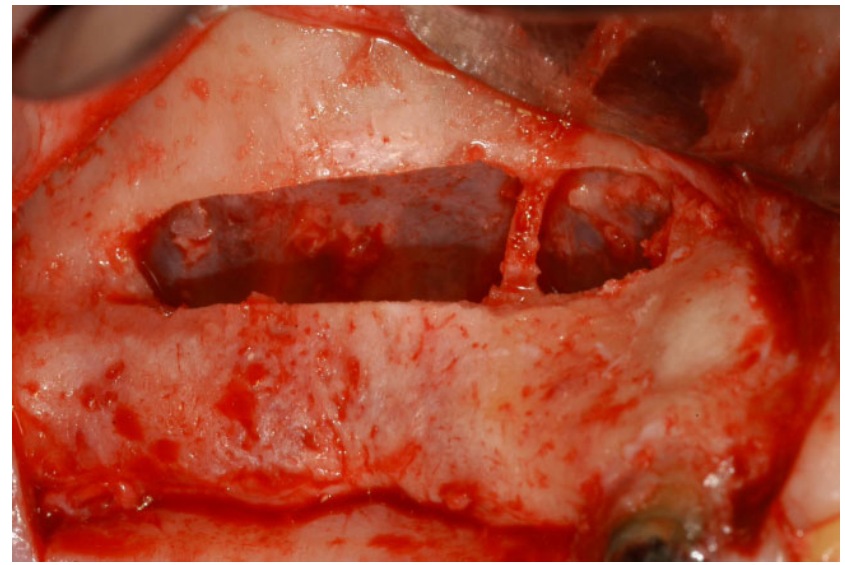

Figure 7 Membrane elevation has been completed using an EL1 ultrasonic insert and hand instrument.

\section{Statistical Analysis}

A web-based software (http://www.dssresearch.com) was used for the calculation of the statistical power of this study. The calculation was performed in 2008 assuming data present at that time in literature as expected percentage of membrane perforation in the two groups (group A, $31 \% ;^{17}$ group B, $7 \%{ }^{15,18}$ ). With a sample of 36 patients per group, this RCT had a power of $84.1 \%$ in detecting a significant intergroup difference (at $\alpha=0.05$ ).

Shapiro-Wilk test was applied to assess data normality, then a two-sided Wilcoxon-Mann-Whitney test and, for analysis of time, a linear regression analysis were used (SPSS ${ }^{\circledR}$ 18, SPSS Inc., Chicago, IL, USA). All patients were included for analysis. The level of significance was set at $\alpha=0.05$.

\section{RESULTS}

Seventy-two patients (age $55.4 \pm 10.1$ years, range $42-73$ years, 44 female, 28 male) underwent unilateral sinus augmentation with lateral approach (44 left, 28 right sinuses). Fifty-one sinuses were classified as class $\mathrm{V}$ and twenty-one as class VI according to Cawood and Howell. ${ }^{20}$ Forty-nine patients were no smokers, fifteen were light smokers, and eight were heavy smokers.

No dropouts were registered in this study. Each clinical operator contributed with 36 patients, with a balanced distribution according to A and B groups. Four perforations of the Schneiderian membrane (11.1\%) were observed in group A (two occurred during membrane elevation with manual instruments) and zero perforations in group B $(p<.05)$. The surgical procedure 
was not abandoned due to membrane perforation in any of the cases. Three out of four perforations were associated with the presence of Underwood's septa $(p<.05)$, which was encountered in 20 cases (27.8\% prevalence; nine in group A [25\%], 11 in group B [30.6\%]). All the four perforations occurred in no smoker patients.

Vascular branches were observed in the antrostomy area in 17 cases $(23.6 \%$ prevalence; five in group $\mathrm{A}$ [13.9\%], 12 in group B [33.3\%]). No evidence of vascular lacerations or profuse bleeding was registered in both groups. Besides membrane perforations, no other complications were registered during the surgical procedures. A shorter surgical time was recorded in group A (9.2 \pm 3.7 minutes) than in group B ( $13.3 \pm 2.4$ minutes; $p<.05)$.

\section{DISCUSSION}

Perforation of Schneiderian membrane is the most common intraoperative complication in sinus floor elevation with lateral window approach. ${ }^{21-23}$ Conflicting data on the clinical significance of sinus lining perforation are present in literature: some studies ${ }^{24-27}$ report higher rates of implant failures in cases with perforations, whereas other authors ${ }^{23,28-30}$ found no differences in implant survival with respect to membrane integrity. Proussaefs and colleagues ${ }^{26,29}$ observed that nonperforated sites demonstrated significantly more bone formation than perforated sites; on the contrary, a recent study by Froum and colleagues ${ }^{30}$ showed that sinus membrane damages, when properly repaired during surgery, did not appear to be an adverse complication in terms of vital bone production. Hernández-Alfaro and colleagues ${ }^{31}$ reported that the implant survival rate is inversely proportional to the size of the membrane perforation; significantly higher implant survival rates were registered when perforations were less than $10 \mathrm{~mm}$ compared with perforations greater than $10 \mathrm{~mm}$. Kim and colleagues ${ }^{32}$ observed that patients who had membrane perforation during sinus augmentation procedure showed a higher incidence of sinusitis, whereas Manor and colleagues $^{33}$ found no statistical correlation between the two situations.

However, Schneiderian membrane integrity after elevation or an adequate repair of eventual perforations is necessary to complete properly the grafting procedure. Large perforations or tears of the sinus lining may result in an abandonment of the surgical procedure, ${ }^{34}$ but smaller lesions can be successfully managed using resorbable membranes ${ }^{34,35}$ or connective tissue grafts, ${ }^{36-38}$ although these options imply an increase in surgical time and treatment costs.

A review of the literature shows that prevalence of Schneiderian membrane perforation during lateral antrostomy performed with rotary intruments (diamond or carbide round burs) varies from 5 to $56 \%{ }^{10,12,13,17,22,23,25,28,30,31,39-54}$ (Table 1). Mean perforation rate, on a total sample of 2,741 sinus elevation surgeries, results to be $24.1 \%$ (weighted average).

The use of a specific piezoelectric surgical unit to perform lateral antrostomy during sinus floor elevation has been described by Vercellotti and colleagues. ${ }^{15}$ Ultrasonic bone cut characteristics seem to be favorable in sinus surgery applications; the limited load applied

\begin{tabular}{|c|c|c|c|}
\hline Author/Year & $\begin{array}{l}\text { Treated } \\
\text { Sinuses }\end{array}$ & Perforations & $\%$ \\
\hline Krekmanov $1995^{39}$ & 70 & 5 & 7.1 \\
\hline van den Bergh $1998^{12}$ & 62 & 3 & 4.8 \\
\hline Khoury $1999^{25}$ & 216 & 51 & 23.6 \\
\hline Wannfors $2000^{40}$ & 40 & 11 & 27.5 \\
\hline van den Bergh $2000^{41}$ & 30 & 6 & 20.0 \\
\hline Raghoebar $2001^{42}$ & 182 & 47 & 25.8 \\
\hline Cho $2001^{22}$ & 49 & 9 & 18.4 \\
\hline Aimetti $2001^{43}$ & 28 & 6 & 21.4 \\
\hline Kasabah $2003^{13}$ & 146 & 82 & 56.2 \\
\hline Philippart $2003^{44}$ & 18 & 6 & 33.3 \\
\hline Hallman $2004^{45}$ & 71 & 11 & 15.5 \\
\hline Schwartz-Arad $2004^{23}$ & 81 & 36 & 44.4 \\
\hline Shlomi $2004^{46}$ & 73 & 21 & 28.8 \\
\hline Papa $2005^{47}$ & 76 & 8 & 10.5 \\
\hline Ardekian $2006^{28}$ & 110 & 35 & 31.8 \\
\hline Barone $2006^{48}$ & 124 & 31 & 25.0 \\
\hline Hernández-Alfaro $2008^{31}$ & 474 & 104 & 21.9 \\
\hline Barone $2008^{17}$ & 13 & 3 & 23.1 \\
\hline Zijderveld $2008^{10}$ & 118 & 13 & 11.0 \\
\hline Becker $2008^{49}$ & 201 & 41 & 20.4 \\
\hline Oh $2011^{50}$ & 175 & 60 & 34.3 \\
\hline Kim $2011^{51}$ & 27 & 7 & 25.9 \\
\hline Yilmaz $2012^{53}$ & 64 & 11 & 17.2 \\
\hline Cha $2012^{54}$ & 217 & 35 & 16.1 \\
\hline Rickert $2013^{52}$ & 36 & 4 & 11.1 \\
\hline Froum $2013^{30}$ & 40 & 15 & 37.5 \\
\hline Total & 2741 & 661 & 24.1 \\
\hline
\end{tabular}


by the operator on the handpiece ${ }^{55,56}$ allows for an easy surgical control, and the selective cut on hard tissues ${ }^{57,58}$ prevents from accidental involvements of delicate structures such as Schneiderian membrane and vascular branches. A literature review on ultrasonic lateral antrostomy shows a perforation rate ranging from 4 to $31 \%^{15-18,52,59-65}$ (Table 2), with a weighted average of $8.1 \%$ on a sample of 542 cases.

In a recent review, Wallace and colleagues ${ }^{66}$ state that utilization of piezoelectric surgery, rather than rotary instruments, for lateral window preparation and membrane separation leads to a dramatic reduction in the occurrence of the intraoperative complications of bleeding and membrane perforation.

Two main surgical approaches in performing ultrasonic antrostomy have been described in literature: an outlining of the bony window on the lateral wall of the sinus ${ }^{15}$ or an erosion of the cortical plate until the dark color of the sinus cavity appears under a thin layer of bone, before outlining the window. ${ }^{18,19}$ The aim of this study was to analyze, in an RCT, the prevalence of intraoperative complications by comparing the two techniques.

Direct piezoelectric outlining of the bony window resulted in $11 \%$ perforation prevalence; on the other hand, erosion of the cortical wall before outlining the window didn't cause any perforation of Schneiderian membrane. These findings are in accordance with data present in literature on ultrasonic lateral approach,

\section{TABLE 2 Membrane Perforation with Ultrasonic}

\section{Instruments}

\begin{tabular}{lrcr} 
Author/Year & $\begin{array}{c}\text { Treated } \\
\text { Sinuses }\end{array}$ & Perforations & $\%$ \\
\hline${\text { Vercellotti } 2001^{15}}^{15}$ & 21 & 1 & 4.8 \\
${\text { Wallace } 2007^{18}}_{\text {Barone 2008 }}^{17}$ & 100 & 7 & 7.0 \\
Blus 2008 & 13 & 4 & 30.8 \\
Stacchi 2008 & 53 & 2 & 3.8 \\
Felice 2009 & 10 & 1 & 10.0 \\
Toscano 2010 & 20 & 2 & 10.0 \\
Sánchez-Recio 2010 & 56 & 2 & 3.6 \\
Sohn 2010 & 26 & 4 & 15.4 \\
Cortes 2012 & 127 & 8 & 6.3 \\
Cassetta $2012^{65}$ & 40 & 2 & 5.0 \\
Rickert 2013 & 40 & 7 & 17.5 \\
Total & 36 & 4 & 11.1 \\
& 542 & 44 & 8.1 \\
\hline
\end{tabular}

where higher perforation rates are reported when direct outlining technique was used. ${ }^{17,62,65}$ A possible explanation could be related to the better visibility and to the easier perception of membrane proximity when using erosion technique; especially with thick cortical walls, these factors result in an enhanced surgical control with a more careful load application on the handpiece, reducing perforation risk. Furthermore, erosion technique could allow for more efficient cooling of the piezoelectric insert in proximity of the membrane, highly susceptible to thermal damages. ${ }^{67}$

In accordance with literature, ${ }^{68-70}$ Underwood's septa were detected in $27.8 \%$ of the cases, but their presence resulted significantly associated with perforations only in group $\mathrm{A}$; in group $\mathrm{B}$, better visibility and easier surgical control could play an important role in simplifying membrane management in these complex situations.

In this trial, smoking appears not to play a role in increasing perforation risk; in fact, in our sample, all the perforations occurred in no smoker patients.

Bleeding deriving from lesions of the anastomosis of the lower branch of the posterior superior alveolar artery and the infraorbital artery is a possible intraoperative complication in sinus elevation surgery. This artery is present in the context of sinusal antero-lateral wall in $100 \%$ of cadaver specimens; ${ }^{11}$ in this study, vascular branches were observed in $23.6 \%$ of the cases (13.9\% in group A and $33.3 \%$ in group B). A greater number of vessels were detected in group B, likely because of the better visibility; however, selective cut with a piezoelectric device prevented hemorrhagic complications in any of the cases in either group.

Finally, surgical time was shorter in group A than in group B; the difference (about 4 minutes) is statistically significant but appears clinically irrelevant.

Analyzing these data, we must reject the null hypothesis of this study; in other words, differences in prevalence of intraoperative complications between the two groups (mainly Schneiderian membrane perforation) are statistically significant in our sample.

\section{CONCLUSIONS}

Within the limits of the present RCT, it may be concluded that ultrasonic erosion of the lateral wall of the sinus is a more predictable technique than piezoelectric outlining of a bone window in preventing from accidental perforations of Schneiderian membrane during sinus augmentation procedures. The presence of Underwood's 
septa seems not to increase risk of perforations when using this technique.

\section{REFERENCES}

1. Amler MH. The time sequence of tissue regeneration in human extraction wounds. Oral Surg Oral Med Oral Pathol 1969; 27:309-318.

2. Trombelli L, Farina R, Marzola A, Bozzi L, Liljenberg B, Lindhe J. Modeling and remodeling of human extraction sockets. J Clin Periodontol 2008; 35:630-639.

3. Schropp L, Wenzel A, Kostopoulos L, Karring T. Bone healing and soft tissue contour changes following singletooth extraction: a clinical and radiographic 12-month prospective study. Int J Periodontics Restorative Dent 2003; 23:313-323.

4. Raja SV. Management of the posterior maxilla with sinus lift: review of techniques. J Oral Maxillofac Surg 2009; 67: 1730-1734.

5. Pramstraller M, Farina R, Franceschetti G, Pramstraller C, Trombelli L. Ridge dimensions of the edentulous posterior maxilla: a retrospective analysis of a cohort of 127 patients using computerized tomography data. Clin Oral Implants Res 2011; 22:54-61.

6. Tatum $\mathrm{OH}$. Lecture presented to the Alabama Implant Congress. 1976.

7. Boyne PJ, James RA. Grafting of the maxillary sinus floor with autogenous marrow and bone. J Oral Surg 1980; 38: 613-616.

8. Pjetursson BE, Tan WC, Zwahlen M, Lang NP. A systematic review of the success of sinus floor elevation and survival of implants inserted in combination with sinus floor elevation. J Clin Periodontol 2008; 35(8 Suppl):216-240.

9. van den Bergh JP, ten Bruggenkate CM, Disch FJ, Tuinzing DB. Anatomical aspects of sinus floor elevations. Clin Oral Implants Res 2000; 11:256-265.

10. Zijderveld SA, van den Bergh JP, Schulten EA, ten Bruggenkate CM. Anatomical and surgical findings and complications in 100 consecutive maxillary sinus floor elevation procedures. J Oral Maxillofac Surg 2008; 66:1426-1438.

11. Rosano G, Taschieri S, Gaudy JF, Weinstein T, Del Fabbro M. Maxillary sinus vascular anatomy and its relation to sinus lift surgery. Clin Oral Implants Res 2011; 22:711-715.

12. van den Bergh JP, ten Bruggenkate CM, Krekeler G, Tuinzing DB. Sinus floor elevation and grafting with autogenous iliac crest bone. Clin Oral Implants Res 1998; 9:429435.

13. Kasabah S, Krug J, Simunek A, Lecaro MC. Can we predict maxillary sinus mucosa perforation? Acta Medica (Hradec Kralove) 2003; 46:19-23.

14. Torrella F, Pitarch J, Cabanes G, Anitua E. Ultrasonic ostectomy for the surgical approach of the maxillary sinus: a technical note. Int J Oral Maxillofac Implants 1998; 13:697-700.
15. Vercellotti T, De Paoli S, Nevins M. The piezoelectric bony window osteotomy and sinus membrane elevation: introduction of a new technique for simplification of the sinus augmentation procedure. Int J Periodontics Restorative Dent $2001 ; 21: 561-567$.

16. Toscano NJ, Holtzclaw D, Rosen PS. The effect of piezoelectric use on open sinus lift perforation: a retrospective evaluation of 56 consecutively treated cases from private practices. J Periodontol 2010; 81:167-171.

17. Barone A, Santini S, Marconcini S, Giacomelli L, Gherlone E, Covani U. Osteotomy and membrane elevation during the maxillary sinus augmentation procedure. A comparative study: piezoelectric device vs. conventional rotative instruments. Clin Oral Implants Res 2008; 19:511-515.

18. Wallace SS, Mazor Z, Froum SJ, Cho SC, Tarnow DP. Schneiderian membrane perforation rate during sinus elevation using piezosurgery: clinical results of 100 consecutive cases. Int J Periodontics Restorative Dent 2007; 27:413419.

19. Vercellotti T. Maxillary sinus lift technique. In: Vercellotti T, ed. Essentials in piezosurgery: clinical advantages in dentistry. Chicago, IL: Quintessence Pub Co, 2009:65-74.

20. Cawood JI, Howell RA. A classification of the edentulous jaws. Int J Oral Maxillofac Surg 1988; 17:232-236.

21. Ziccardi VB, Betts NJ. Complications of maxillary sinus augmentation. In: Jensen OT, ed. The sinus bone graft. 1st ed. Chicago, IL: Quintessence, 1999:201-208.

22. Cho SC, Wallace SS, Froum SJ, Tarnow DP. Influence of anatomy on Schneiderian membrane perforations during sinus elevation surgery: three-dimensional analysis. Pract Proced Aesthet Dent 2001; 13:160-163.

23. Schwartz-Arad D, Herzberg R, Dolev E. The prevalence of surgical complications of the sinus graft procedure and their impact on implant survival. J Periodontol 2004; 75:511-516.

24. Jensen OT, Shulman LB, Block MS, Iacono VJ. Report of the Sinus Consensus Conference of 1996. Int J Oral Maxillofac Implants 1998; 13(Suppl):11-45.

25. Khoury F. Augmentation of the sinus floor with mandibular bone block and simultaneous implantation: a 6-year clinical investigation. Int J Oral Maxillofac Implants 1999; 14:557564.

26. Proussaefs P, Lozada J, Kim J, Rohrer MD. Repair of the perforated sinus membrane with a resorbable collagen membrane: a human study. Int J Oral Maxillofac Implants 2004; 19:413-420.

27. Cho-Lee GY, Naval-Gias L, Castrejon-Castrejon S, et al. A 12-year retrospective analytic study of the implant survival rate in 177 consecutive maxillary sinus augmentation procedures. Int J Oral Maxillofac Implants 2010; 25:1019-1027.

28. Ardekian L, Oved-Peleg E, Machtei EE, Peled M. The clinical significance of sinus membrane perforation during augmentation of the maxillary sinus. J Oral Maxillofac Surg 2006; 64:277-282. 
29. Proussaefs P, Lozada J, Kim J. Effects of sealing the perforated sinus membrane with a resorbable collagen membrane: a pilot study in humans. J Oral Implantol 2003; 29:235-241.

30. Froum S, Khouly I, Favero G, Cho SC. Effect of maxillary sinus membrane perforation on vital bone formation and implant survival: a retrospective study. J Periodontol 2013; 84:1094-1099. DOI: 10.1902/jop.2012.120458

31. Hernández-Alfaro F, Torradeflot MM, Marti C. Prevalence and management of Schneiderian membrane perforations during sinus-lift procedures. Clin Oral Implants Res 2008; 19:91-98.

32. Kim YK, Hwang JY, Yun PY. Relationship between prognosis of dental implants and maxillary sinusitis associated with the sinus elevation procedure. Int J Oral Maxillofac Implants 2013; 28:178-183.

33. Manor Y, Mardinger O, Bietlitum I, Nashef A, Nissan J, Chaushu G. Late signs and symptoms of maxillary sinusitis after sinus augmentation. Oral Surg Oral Med Oral Pathol Oral Radiol Endod 2010; 110:e1-e4.

34. Vlassis JM, Fugazzotto PA. A classification system for sinus membrane perforations during augmentation procedures with options for repair. J Periodontol 1999; 70:692-699.

35. Testori T, Wallace SS, Del Fabbro M, et al. Repair of large sinus membrane perforations using stabilized collagen barrier membranes: surgical techniques with histologic and radiographic evidence of success. Int J Periodontics Restorative Dent 2008; 28:9-17.

36. Kim YK, Hwang JW, Yun PY. Closure of large perforation of sinus membrane using pedicled buccal fat pad graft: a case report. Int J Oral Maxillofac Implants 2008; 23:11391142.

37. Biglioli F, Pedrazzoli M, Colletti G. Repair of a perforated sinus membrane with a palatal fibromucosal graft: a case report. Minerva Stomatol 2010; 59:299-304.

38. Gehrke SA, Taschieri S, Del Fabbro M, Corbella S. Repair of a perforated sinus membrane with a subepithelial palatal conjunctive flap: technique report and evaluation. Int J Dent 2012; 2012:489762. DOI: 10.1155/2012/489762

39. Krekmanov L. A modified method of simultaneous bone grafting and placement of endosseous implants in the severely resorbed maxilla. Int J Oral Maxillofac Implants 1995; 10:682-688.

40. Wannfors K, Johansson B, Hallman M, Strandkvist T. A prospective randomized study of 1- and 2-stage sinus inlay bone grafts: 1-year follow-up. Int J OralMaxillofac Implants 2000; 15:625-632.

41. van den Bergh JPA, ten Bruggenkate CM, Krekeler G, Tuinzing DB. Maxillary sinus floor elevation and grafting with human demineralized freeze-dried bone. Clin Oral Implants Res 2000; 11:487-493.

42. Raghoebar GM, Timmenga NM, Reintsema H, Stegenga B, Vissink A. Maxillary bone grafting for insertion of endosseous implants: results after 12-124 months. Clin Oral Implants Res 2001; 12:279-286.

43. Aimetti M, Romagnoli R, Ricci G, Massei G. Maxillary sinus elevation: the effect of macrolacerations and microlacerations of the sinus membrane as determined by endoscopy. Int J Periodontics Restorative Dent 2001; 21:581-589.

44. Philippart P, Brasseur M, Hoyaux D, Pochet R. Human recombinant tissue factor, platelet-rich plasma, and tetracycline induce a high-quality human bone graft: a 5-year survey. Int J Oral Maxillofac Implants 2003; 18:411-416.

45. Hallman M, Nordin T. Sinus floor augmentation with bovine hydroxyapatite mixed with fibrin glue and later placement of nonsubmerged implants: a retrospective study in 50 patients. Int J Oral Maxillofac Implants 2004; 19:222227.

46. Shlomi B, Horowitz I, Kahn A, Dobriyan A, Chaushu G. The effect of sinus membrane perforation and repair with Lambone on the outcome of maxillary sinus floor augmentation: a radiographic assessment. Int J Oral Maxillofac Implants 2004; 19:559-562.

47. Papa F, Cortese A, Maltarello MC, Sagliocco R, Felice P, Claudio PP. Outcome of 50 consecutive sinus lift operations. Br J Oral Maxillofac Surg 2005; 43:309-313.

48. Barone A, Santini S, Sbordone L, Crespi R, Covani U. A clinical study of the outcomes and complications associated with maxillary sinus augmentation. Int J Oral Maxillofac Implants 2006; 21:81-85.

49. Becker ST, Terheyden H, Steinriede A, Behrens E, Springer I, Wiltfang J. Prospective observation of 41 perforations of the Schneiderian membrane during sinus floor elevation. Clin Oral Implants Res 2008; 19:1285-1289.

50. Oh E, Kraut RA. Effect of sinus membrane perforation on dental implant integration: a retrospective study on 128 patients. Implant Dent 2011; 20:13-19.

51. Kim YK, Kim SG, Park JY, Yi YJ, Bae JH. Comparison of clinical outcomes of sinus bone graft with simultaneous implant placement: 4-month and 6-month final prosthetic loading. Oral Surg Oral Med Oral Pathol Oral Radiol Endod 2011; 111:164-169.

52. Rickert D, Vissink A, Slater JJ, Meijer HJ, Raghoebar GM. Comparison between conventional and piezoelectric surgical tools for maxillary sinus floor elevation. A randomized controlled clinical trial. Clin Implant Dent Relat Res 2013; 15:297-302. DOI: 10.1111/j.1708-8208.2011.00364.x

53. Yilmaz HG, Tözüm TF. Are gingival phenotype, residual ridge height, and membrane thickness critical for the perforation of maxillary sinus? J Periodontol 2012; 83: 420-425.

54. Cha HS, Kim A, Nowzari H, Chang HS, Ahn KM. Simultaneous sinus lift and implant installation: prospective study of consecutive two hundred seventeen sinus lift and four hundred sixty-two implants. Clin Implant Dent Relat Res 2012. DOI: $10.1111 /$ cid.12012 
55. Parmar D, Mann M, Walmsley AD, Lea SC. Cutting characteristics of ultrasonic surgical instruments. Clin Oral Implants Res 2011; 22:1385-1390.

56. Claire S, Lea SC, Walmsley AD. Characterisation of bone following ultrasonic cutting. Clin Oral Investig 2013; 17: 905-912. DOI: 10.1007/s00784-012-0754-9

57. Stübinger S, Kuttenberger J, Filippi A, Sader R, Zeilhofer HF. Intraoral piezosurgery: preliminary results of a new technique. J Oral Maxillofac Surg 2005; 63:1283-1287.

58. Schaeren S, Jaquiéry C, Heberer M, Tolnay M, Vercellotti T, Martin I. Assessment of nerve damage using a novel ultrasonic device for bone cutting. J Oral Maxillofac Surg 2008; 66:593-596.

59. Blus C, Szmukler-Moncler S, Salama M, Salama H, Garber D. Sinus bone grafting procedures using ultrasonic bone surgery: 5-year experience. Int J Periodontics Restorative Dent 2008; 28:221-229.

60. Stacchi C, Orsini G, Di Iorio D, Breschi L, Di Lenarda R. Clinical, histologic, and histomorphometric analyses of regenerated bone in maxillary sinus augmentation using fresh frozen human bone allografts. J Periodontol 2008; 79:1789-1796.

61. Felice P, Scarano A, Pistilli R, et al. A comparison of two techniques to augment maxillary sinuses using the lateral window approach: rigid synthetic resorbable barriers versus anorganic bovine bone. Five-month post-loading clinical and histological results of a pilot randomised controlled clinical trial. Eur J Oral Implantol 2009; 2:293-306.

62. Sánchez-Recio C, Peñarrocha-Diago M, Peñarrocha-Diago $\mathrm{M}$, Peñarrocha-Oltra D. Maxillary sinus lift performed using ultrasound. Evaluation of 21 patients. Med Oral Patol Oral Cir Bucal 2010; 15:e371-e374.
63. Sohn DS, Moon JW, Lee HW, Choi BJ, Shin IH. Comparison of two piezoelectric cutting inserts for lateral bony window osteotomy: a retrospective study of 127 consecutive sites. Int J Oral Maxillofac Implants 2010; 25:571-576.

64. Cortes AR, Cortes DN, Arita ES. Effectiveness of piezoelectric surgery in preparing the lateral window for maxillary sinus augmentation in patients with sinus anatomical variations: a case series. Int J Oral Maxillofac Implants 2012; 27: 1211-1215.

65. Cassetta M, Ricci L, Iezzi G, Calasso S, Piattelli A, Perrotti V. Use of piezosurgery during maxillary sinus elevation: clinical results of 40 consecutive cases. Int J Periodontics Restorative Dent 2012; 32:e182-e188.

66. Wallace SS, Tarnow DP, Froum SJ, et al. Maxillary sinus elevation by lateral window approach: evolution of technology and technique. J Evid Based Dent Pract 2012; 12(3 Suppl):161-171.

67. Tomazic PV, Hammer GP, Gerstenberger C, Koele W, Stammberger H. Heat development at nasal endoscopes' tips: danger of tissue damage? A laboratory study. Laryngoscope 2012; 122:1670-1673.

68. Shibli JA, Faveri M, Ferrari DS, et al. Prevalence of maxillary sinus septa in 1024 subjects with edentulous upper jaws: a retrospective study. J Oral Implantol 2007; 33:293296.

69. Koymen R, Gocmen-Mas N, Karacayli U, Ortakoglu K, Ozen T, Yazici AC. Anatomic evaluation of maxillary sinus septa: surgery and radiology. Clin Anat 2009; 22:563-570. DOI: 10.1002/ca.20813.

70. Rosano G, Gaudy JF, Chaumanet G, Del Fabbro M, Taschieri S. Maxillary sinus septa. Prevalence and anatomy. Rev Stomatol Chir Maxillofac 2012; 113:32-35. 